\title{
Implementation strategies to improve cervical cancer prevention in sub-Saharan Africa: a systematic review
}

\author{
Lauren G. Johnson", Allison Armstrong, Caroline M. Joyce, Anne M. Teitelman and Alison M. Buttenheim
}

\begin{abstract}
Background: Developed countries, such as the USA, have achieved significant decreases in cervical cancer burden since the introduction of Pap smear-based programs in the 1960s. Due to implementation barriers and limited resources, many countries in sub-Saharan Africa (SSA) have been unable to attain such reductions. The purpose of this review is to evaluate implementation strategies used to improve the uptake and sustainability of cervical cancer prevention programs in SSA.

Methods: A reviewer (LJ) independently searched PubMed, Ovid/MEDLINE, Scopus, and Web of Science databases for relevant articles with the following search limits: English language, peer reviewed, and published between 1996 and 2017. The 4575 search results were screened for eligibility (CJ, LJ) to identify original research that empirically evaluated or tested implementation strategies to improve cervical cancer prevention in SSA. Fifty-three articles met criteria for inclusion in the final review. AA, CJ, and LJ abstracted the included articles for implementation-related content and evaluated them for risk of bias according to study design with the National Heart, Lung, and Blood Institute's (NHLBI) Quality Assessment Tools. Results were reported according to PRISMA guidelines.
\end{abstract}

Results: The 53 included studies are well represented among all sub-Saharan regions: South $(n=16,30.2 \%)$, West $(n=16,30.2 \%)$, East $(n=14,26.4 \%)$, and Middle $(n=7,13.2 \%)$. There are 34 cross-sectional studies (64.2\%), 10 preposttests (18.9\%), 8 randomized control trials (15.1\%), and one nonrandomized control trial (1.9\%). Most studies are "fair" quality $(n=22,41.5 \%)$. Visual inspection with acetic acid (VIA) $(n=19,35.8 \%)$ was used as the main prevention method more frequently than HPV DNA/mRNA testing $(n=15,28.3 \%)$, Pap smear $(n=13,24.5 \%)$, and HPV vaccine $(n=9,17.0 \%)$. Effectiveness of strategies to improve program implementation was measured using implementation outcomes of penetration $(n=33,62.3 \%)$, acceptability $(n=15,28.3 \%)$, fidelity $(n=14,26.4 \%)$, feasibility $(n=8,15.1 \%)$, adoption $(n=6,11.3 \%)$, sustainability $(n=2,3.8 \%)$, and cost $(n=1,1.9 \%)$. Education strategies $(n=38,71.7 \%)$ were used most often but have shown limited effectiveness.

Conclusion: This systematic review highlights the need to diversify strategies that are used to improve implementation for cervical cancer prevention programs. While education is important, implementation science literature reveals that education is not as effective in generating change. There is a need for additional organizational support to further incentivize and sustain improvements in implementation.

Keywords: Cervical cancer, Prevention, Program implementation, Implementation strategies, Sub-Saharan Africa

\footnotetext{
* Correspondence: Igjohnson14@gmail.com

School of Nursing, University of Pennsylvania, Philadelphia, PA, USA
} 


\section{Background}

Cervical cancer is a high-burden global health issue, with an estimated 528,000 new cases and 266,000 deaths in 2012 for women across the world [1]. Most of the global burden (85\%) lies in less developed countries, with regions in sub-Saharan Africa (SSA) having the largest age-standardized incidence and mortality rates [1]. Developed countries, such as the USA, have achieved significant decreases in cervical cancer burden since the introduction of organized Pap smear programs in the 1960s [2, 3]. However, many countries in SSA have been unable to attain such reductions due to implementation barriers and resource limitations [4-8]. In fact, cervical cancer rates are expected to continue rising despite efforts to implement national screening and treatment programs [9]. Cervical cancer remains the most commonly diagnosed cancer and leading cause of cancerrelated death in African women south of the Sahara [1].

Untangling the causes for high cervical cancer burden in SSA is difficult due to a complex interplay of many biological, organizational, economic, and sociocultural factors. For example, HIV has been correlated with an increased risk for developing cervical cancer [10]. HIV infection causes the body to become immunocompromised and more susceptible to contracting HPV, which is a significant precursor to cervical cancer [10]. SSA incidentally carries a high HIV/AIDS burden, accounting for $71 \%$ of the global population living with HIV [11]. Furthermore, young women bear a disproportionate HIV burden compared to their male peers [11]. Other contributory factors include the aging and growth of the population, limited access to medical facilities, poor nutrition, severity of disease at presentation, and insufficient facilities for treatment [12-15]. While these factors contribute to the rise in cervical cancer for this region, this paper focuses on the need for improved implementation of existing prevention programs and the promise that increased access to preventive services has on decreasing burden.

Prevention is key. With adequate resources, precancerous cervical lesions are easily prevented and treatable $[16,17]$. The incubation period between HPV infections developing into cervical cancer is 10 to 20 years, which allows ample opportunities to screen, track, and treat across the disease progression [18]. In addition, numerous technologies have been developed to detect and treat precancerous lesions including Pap smear, colposcopy, visual inspection with acetic acid or Lugol's iodine (VIA/VILI), HPV DNA testing, cone biopsy, cryotherapy, and loop electrosurgical incision procedure (LEEP) $[2,19]$. Although these tools have been proven safe and effective [20], there are still significant challenges in implementing them into comprehensive national screening and treatment programs.
For decades, developed countries have used cytologybased programs with Pap smear as the standard screening protocol [2, 3, 8]. However, these programs require lab infrastructure that is not readily available in many SSA countries and is often prohibitively expensive to sustain on a large scale [21]. Alternative screening methods have been developed with the hope of being more sustainable in resource-limited settings [8]. Visual inspection with acetic acid and Lugol's iodine (VIA/VILI) are visual tests that are used to identify precancerous lesions with the naked eye. VIA and VILI are advantageous because they can be performed by non-physician providers (addressing provider shortages) and provide immediate results (reducing loss to follow-up) [22-24]. VIA and VILI have similar sensitivity when compared to Pap smear and can provide screening at a much lower cost and with fewer staff needed [20, 24, 25]. However, these visual tests are less specific and can lead to overtreatment [20, 24]. HPV DNA testing is another alternative screening method that is used to identify high risk, carcinogenic HPV (typically types 16 and 18). The test can be performed at home with self-sampling kits and has been acceptable for many surveyed women [26-31]. It can also be used as a preliminary triage to save time and resources on women that screen HPV negative and do not require follow-up testing $[32,33]$. HPV DNA testing does not require the same level of lab infrastructure as Pap smear, but it involves lab processing nonetheless and wait times to receive results [8].

Despite development of alternatives to Pap smear, a significant research-to-practice gap still exists. Lack of trained providers, overburdened health facilities, insufficient supplies, inadequate lab infrastructure, loss to treatment follow-up, high costs, and cultural beliefs are some of the implementation barriers experienced in SSA [4-8]. In addition to seeking alternative screening methods, SSA countries can further improve their prevention efforts by developing and employing implementation strategies to overcome these barriers. An implementation strategy is defined as "a systematic intervention process to adopt and integrate evidence-based health innovations into usual care" [34]. The purpose of this systematic review is to uncover the breadth and diversity of implementation strategies used to improve the uptake and sustainability of cervical cancer prevention programs in SSA. Through highlighting different strategies, we aim to assist researchers, practitioners, managers, and policy makers in scaling up and evaluating new and existing programs.

\section{Methods}

\section{Search strategy}

Figure 1 outlines the search strategy, which has been reported according to Preferred Reporting Items for Systematic Reviews and Meta-Analyses (PRISMA) guidelines $[35,36]$. A reviewer (LJ) independently searched 


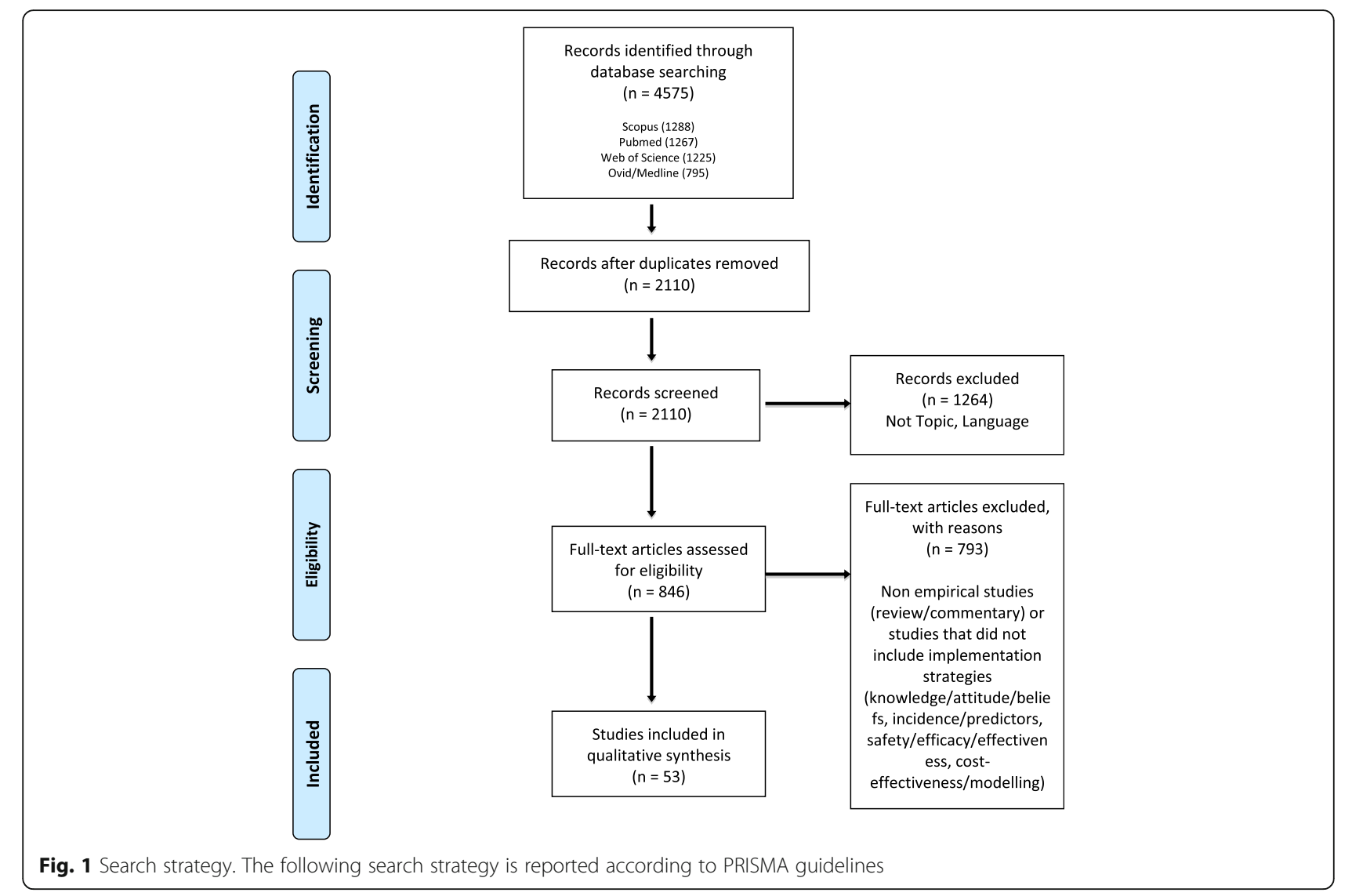

PubMed, Ovid/MEDLINE, Scopus, and Web of Science databases with the following approximate search terms: (cervical cancer OR HPV) AND (prevention OR screening OR program OR implementation OR scale-up OR Pap smear OR VIA OR VILI OR see-and-treat OR HPV vaccine OR HPV DNA test OR self-sampling OR colposcopy OR cryotherapy OR LEEP) AND (sub-Saharan Africa OR country-specific terms for each SSA country). Search strategies with specific terminology for each database are included as Additional file 1.

\section{Eligibility criteria}

Inclusion and exclusion criteria were developed to identify original research that empirically evaluated or tested implementation strategies to improve cervical cancer prevention in SSA. Articles were eligible for inclusion if written in English, peer reviewed, and published between 1996 and 2017. Non-empirical studies (reviews, commentaries, editorials, etc.) and studies that did not explicitly assess implementation strategies (knowledge, attitudes, and beliefs; incidence and prevalence; safety and efficacy; cost effectiveness and modeling) were excluded from the review.

\section{Study selection}

The initial database search yielded 4575 results. Two reviewers $(\mathrm{CJ}, \mathrm{LJ})$ conducted the study selection process.
Titles and abstracts of the identified articles were screened to exclude duplicates $(n=2465)$ and studies not relevant to the topic $(n=1264)$. The remaining articles $(n=846)$ were reviewed in full text. Fifty-three studies met the eligibility criteria and an additional 793 articles were excluded.

\section{Data extraction}

The 53 articles that fit the inclusion criteria were extracted for the following implementation-related content: title, author, publication year, purpose, country, study design, prevention tools, implementation strategies, implementation outcomes, and results. The primary reviewer (LJ) and two additional reviewers (AA, CJ) completed data extraction for a sample of initial articles $(n=11,20 \%)$ to ensure accuracy. Inconsistencies were resolved through consensus before the primary reviewer proceeded with the remaining articles. Results were summarized in frequency tables.

Two seminal articles from implementation science, Proctor et al. [37] and Powell et al. [34], were used to define and categorize implementation outcomes and strategies, respectively. Based on the Conceptual Model of Implementation Research [38], Proctor et al. developed a taxonomy of implementation outcomes that are conceptually distinct from service system outcomes and clinical treatment 
outcomes. Implementation outcomes were defined as "the effects of deliberate and purposive actions to implement new treatments, practices, and services." Using an iterative process of reading and discussing relevant literature in behavioral and health science, the working group of implementation researchers defined eight implementation outcomes: acceptability, adoption, appropriateness, costs, feasibility, fidelity, penetration, and sustainability. Powell et al. used the Consolidated Framework for Implementation Research [39] to compile a list of implementation strategies, or "systematic intervention processes to adopt and integrate evidence-based health innovations into usual care." A working group of researchers and clinicians from health and mental services used narrative review to develop six categories: educate, restructure, quality, finance, plan, and attend to policy context. A complete list of categories and their definitions for implementation outcomes and strategies can be found in Table 1 .

\section{Quality screening}

Quality assessment tools from the National Heart, Lung, and Blood Institute (NHLBI) were used to assess each study for internal validity [40]. There are separate NHLBI Quality Assessment Tools for each study type (controlled trials, preposttest, and cross-sectional). Each tool includes specific questions to assess bias, confounding, power, and strength of association between intervention and outcomes. The answer to each question can be "yes," "no," "cannot determine," "not reported," or "not applicable." Instead of using a numeric scoring system, the rater is asked to consider potential risk for bias in the study design whenever a "no" is selected. Overall quality ratings are scored as "good" (low risk of bias, valid results), "fair" (some risk of bias, does not invalidate results), or "poor" (significant risk for bias, may invalidate results). One reviewer (LJ) independently screened all studies, and two additional reviewers (AA, CJ) screened a $20 \%$ sample $(n=11)$ to double check for accuracy.

Table 1 Implementation outcomes and strategies

\begin{tabular}{|c|c|}
\hline Implementation outcome & Definition $^{a}$ \\
\hline Acceptability & $\begin{array}{l}\text { Perception among implementation stakeholders that a given treatment, service, practice, or innovation is agreeable, } \\
\text { palatable, or satisfactory }\end{array}$ \\
\hline Appropriateness & $\begin{array}{l}\text { Perceived fit, relevance, or compatibility of the innovation or evidence based practice setting, provider, or consumer } \\
\text { and/or perceived fit of innovation to address a particular issue }\end{array}$ \\
\hline Penetration & $\begin{array}{l}\text { Integration of a practice within a service setting and its subsystems; number of eligible persons who use a service, } \\
\text { divided by the total number of persons eligible for the service; number of providers who deliver a given service or } \\
\text { treatment, divided by the total number of providers trained in or expected to deliver the service }\end{array}$ \\
\hline Feasibility & $\begin{array}{l}\text { Extent to which a new treatment, or an innovation, can be successfully used or carried out within a given agency } \\
\text { or setting }\end{array}$ \\
\hline Fidelity & $\begin{array}{l}\text { Degree to which an intervention was implemented as it was prescribed in the original protocol or as it was intended by } \\
\text { the program developers }\end{array}$ \\
\hline Sustainability & $\begin{array}{l}\text { Extent to which a newly implemented treatment is maintained or institutionalized within a service setting's ongoing } \\
\text { stable operations }\end{array}$ \\
\hline Implementation cost & Cost impact of an implementation effort \\
\hline Implementation strategy & Definition $^{a}$ \\
\hline $\begin{array}{l}\text { Plan } \\
\text { - Gather information } \\
\text { - Build buy-in } \\
\text { - Initiate leadership } \\
\text { - Develop relationships }\end{array}$ & $\begin{array}{l}\text { Help stakeholders gather data, select strategies, build buy-in, initiate leadership, and develop the relationships necessary } \\
\text { for successful implementation }\end{array}$ \\
\hline $\begin{array}{l}\text { Educate } \\
\text { - Develop materials } \\
\text { - Inform and influence } \\
\text { stakeholders }\end{array}$ & Inform a range of stakeholders about the innovation and/or implementation effort \\
\hline $\begin{array}{l}\text { Finance } \\
\text { - Modify incentives } \\
\text { - Facilitate financial } \\
\quad \text { support }\end{array}$ & Incentivize the use of clinical innovations and provide resources for training and ongoing support. \\
\hline Restructure & Facilitate implementation by altering staffing, professional roles, physical structures, equipment, and data systems \\
\hline Quality management & $\begin{array}{l}\text { Put data systems and support networks in place to continually evaluate and enhance quality of care, and ensure } \\
\text { that clinical innovations are delivered with fidelity }\end{array}$ \\
\hline Attend to policy context & ccourage the promotion of clinical innovations through accrediting bodies, licensing boards, and legal system \\
\hline
\end{tabular}

${ }^{a}$ Definitions for implementation outcomes and strategies have been cited in Proctor et al. [37] and Powell et al. [34], respectively 


\section{Results}

Of the initial 4575 articles (2110 after duplicates removed), 53 met inclusion criteria and were included in the following synthesis of results. Study characteristics are summarized in Table 2. The table of evidence is included as Table 3. Most studies were published within the last 7 years. Studies were well represented in all regions of sub-Saharan Africa with 16 of the total studies (30.2\%) conducted in Southern Africa, 16 (30.2\%) in Western, 14 (26.4\%) in Eastern, and 7 (13.2\%) in Middle.

\section{Study design}

The majority of studies included in the review are crosssectional $(n=34,64.2 \%)$. Ten of the cross-sectional studies similarly evaluated the impact of changing service providers on how well the screening test is performed. Using specificity and sensitivity rates, some studies compared VIA assessments between nurses and an expert physician $[22,24,25,41]$ while others compared self- vs. physician-collected samples for HPV DNA testing [27, 28, 30, 31, 42, 43]. Sixteen studies examined if screening coverage increases when changing service sites [44-49], combining screening with an already established program (i.e., HIV/STI screening) [50-57], or providing financial incentives [58, 59]. Four studies evaluated the effect of educational interventions on knowledge, attitudes, and screening behaviors for patients [60] and providers [61-63]. Three studies examined if reminder systems can help to decrease lost to follow-up rates through community health workers [64, 65] or phone-based tracking [23]. One study, Michelow et al. [66], used rapid review of reportedly negative cervical smears as an internal quality assurance modality.

Ten studies (18.9\%) were conducted with a preposttest design. All of the pre-post studies evaluated the effectiveness of educational interventions in improving awareness and screening behaviors for patients [67-74] or knowledge and skills retention for providers [75, 76]. Only three studies included a control group $[67,69,70]$.

There are eight randomized control trials (15.1\%). Six trials tested strategies to increase screening uptake through educational interventions [26, 77-79], financial incentivizes [80], or changing service sites [81]. Two trials compared HPV DNA self-sampling to the current standard of physician collection via speculum exam [29, 82].

Only one study is a non-randomized control trial (1.9\%). Mutyaba et al. [83] evaluated if male partner involvement is effective in reducing loss to follow-up after a positive VIA screening test.

\section{Prevention tools}

Primary prevention with HPV vaccine was included in 9 studies (17.0\%). VIA was the most frequently used secondary screening method $(n=19,35.8 \%)$. Less commonly, secondary screening was completed with HPV DNA/mRNA testing $(n=15,28.3 \%)$, Pap smear $(n=13$, $24.5 \%)$, VILI $(n=9,17.0 \%)$, colposcopy $(n=7,13.2 \%)$, biopsy $(n=5,9.4 \%)$, and unspecified screening $(n=5,9.4 \%)$. Digital imaging to supplement visual screening methods (VIA/VILI) was used in 9 studies (17.0\%). If follow-up treatment of precancerous lesions was conducted, it was either performed with LEEP $(n=5,9.4 \%)$ or cryotherapy $(n=5,9.4 \%)$.

\section{Implementation strategies}

Researchers used educate $(n=38,71.7 \%)$, restructure ( $n=26,49.1 \%)$, and quality $(n=13,24.5 \%)$ strategies most frequently in their studies. For patients and their families, education strategies aimed to increase cervical cancer awareness and the importance of prevention. For providers, education strategies were used to improve knowledge and skills retention in conducting screening and treatment services such as VIA, cryotherapy, and LEEP. Example educate strategies include community outreach, individual patient teaching and counseling, provider training, mass media campaigns, and development of educational materials. Restructure strategies were used to facilitate implementation by changing service sites (established vs. mobile clinic for Pap smear), changing delivery models (age- vs. class-based for HPV vaccine), or changing providers (nurse vs. physician for VIA, patient vs. physician for HPV DNA test). Several studies also used the restructure strategy to combine cervical cancer prevention with other services (i.e., HIV/STI testing, marriage counseling, family planning) to improve the financial and infrastructural support provided through already established programs. The quality strategies included in these studies were ongoing consultation, patient reminder systems, and audit-feedback mechanisms. Five studies (9.4\%) included a finance strategy to incentivize patients to uptake screening services. Only one study (1.9\%) utilized the plan strategy. Kapambwe et al. [60] spent time developing trust with alangizi (traditional marriage counselors) to encourage them to integrate cervical cancer screening messaging into their counseling sessions with women. There were no policy strategies $(0 \%)$ in the included studies.

\section{Implementation outcomes}

The most studied implementation outcomes were penetration ( $n=33,62.3 \%)$, acceptability $(n=15,28.3 \%)$, and fidelity ( $n=14,26.4 \%$ ). Penetration was often measured as vaccine or screening coverage, which is calculated by dividing the number of women who participated by the total eligible or targeted population. Additional measures of penetration included rates of loss to follow-up for cryotherapy or LEEP treatment and three-dose adherence for HPV vaccination. Acceptability was most 
Table 2 Study characteristics

\begin{tabular}{|c|c|c|}
\hline & $\begin{array}{l}\text { Number of } \\
\text { studies }(n)\end{array}$ & $\begin{array}{l}\text { Percentage of } \\
\text { total studies (\%) }\end{array}$ \\
\hline \multicolumn{3}{|l|}{ Sub-Saharan region } \\
\hline South & 16 & 30.2 \\
\hline West & 16 & 30.2 \\
\hline East & 14 & 26.4 \\
\hline Middle & 7 & 13.2 \\
\hline \multicolumn{3}{|l|}{ Country } \\
\hline South Africa & 14 & 26.4 \\
\hline Nigeria & 10 & 18.9 \\
\hline Cameroon & 7 & 13.2 \\
\hline Kenya & 5 & 9.4 \\
\hline Uganda & 4 & 7.5 \\
\hline Ghana & 3 & 5.7 \\
\hline Botswana & 2 & 3.8 \\
\hline Tanzania & 1 & 1.9 \\
\hline Cote d'Ivoire & 1 & 1.9 \\
\hline Zambia & 1 & 1.9 \\
\hline Gambia & 1 & 1.9 \\
\hline Mozambique & 1 & 1.9 \\
\hline Malawi & 1 & 1.9 \\
\hline Madagascar & 1 & 1.9 \\
\hline Mali & 1 & 1.9 \\
\hline \multicolumn{3}{|l|}{ Publication date } \\
\hline 1996-2000 & 1 & 1.9 \\
\hline $2001-2005$ & 2 & 3.8 \\
\hline $2006-2010$ & 8 & 15.1 \\
\hline $2011-2017$ & 42 & 79.2 \\
\hline \multicolumn{3}{|l|}{ Study design } \\
\hline Cross-sectional & 34 & 64.2 \\
\hline Pre-post test & 10 & 18.9 \\
\hline Randomized control trial & 8 & 15.1 \\
\hline Nonrandomized control trial & 1 & 1.9 \\
\hline \multicolumn{3}{|l|}{ Prevention tool } \\
\hline VIA & 19 & 35.8 \\
\hline HPV DNA or RNA test & 15 & 28.3 \\
\hline Pap smear & 13 & 24.5 \\
\hline HPV vaccine & 9 & 17.0 \\
\hline Digital imaging & 9 & 17.0 \\
\hline VILI & 9 & 17.0 \\
\hline Colposcopy & 7 & 13.2 \\
\hline Cryotherapy & 5 & 9.4 \\
\hline LEEP & 5 & 9.4 \\
\hline Biopsy & 5 & 9.4 \\
\hline Unspecified screening & 5 & 9.4 \\
\hline
\end{tabular}

Table 2 Study characteristics (Continued)

\begin{tabular}{lll}
\hline & $\begin{array}{l}\text { Number of } \\
\text { studies }(n)\end{array}$ & $\begin{array}{l}\text { Percentage of } \\
\text { total studies (\%) }\end{array}$ \\
\hline $\begin{array}{lll}\text { Implementation strategy } \\
\text { Educate }\end{array}$ & 38 & 71.7 \\
Restructure & 26 & 49.1 \\
Quality & 13 & 24.5 \\
Finance & 5 & 9.4 \\
Plan & 1 & 1.9 \\
Attend to policy context & 0 & 0.0 \\
Implementation outcome & & \\
Penetration & 33 & 62.3 \\
Acceptability & 15 & 28.3 \\
Fidelity & 14 & 26.4 \\
Feasibility & 8 & 15.1 \\
Adoption & 6 & 11.3 \\
Sustainability & 2 & 3.8 \\
Cost & 1 & 1.9 \\
Appropriateness & 0 & 0.0 \\
Quality assessment & 20 & 37.7 \\
Poor & & 20.8 \\
Fair & 20 & \\
Good & & \\
\hline
\end{tabular}

commonly measured by surveying patients to determine reasons why they accepted or refused participation. Among providers, acceptability was measured as comfort with performing newly learned skills and reported satisfaction with training and program implementation. Fidelity was measured in studies that compared either nurses' VIA assessments or self-collected HPV DNA samples to that of expert physicians. These comparisons indicated whether patients and nurses could perform these tests with reasonable reliability and help to address physician shortages by alternatively implementing the screenings.

Other less frequently studied outcomes included feasibility $(n=8,15.1 \%)$, adoption $(n=6,11.3 \%)$, sustainability $(n=2,3.8 \%)$, and cost $(n=1,1.9 \%)$. To measure feasibility, many researchers determined providers' perceived barriers and facilitators to implementation. Other studies quantified circumstances that impeded successful operation of the program such as rates of equipment malfunction, poor picture quality for digital images, invalid lab results, and expired vaccines. Adoption was measured as the willingness or intent of patients to participate in screening or HPV vaccination. Only two studies included measures of sustainability. Moon et al. [54] quantified sustainability by the number of providers that were still performing VIA 1 year after initial 
training. Levine et al. [75] determined VIA skill and knowledge retention with a 6-month follow-up assessment. One study, Goldhaber-Fiebert et al. [65], measured costs associated with cervical cancer screening, i.e., community health worker home visits.

There were no studies that measured appropriateness (0).

\section{Quality assessment}

Few studies $(n=11,20.8 \%)$ were determined to be of "good" quality using the NHLBI Quality Assessment Tools. The remaining studies were "fair" $(n=22,41.5 \%)$ or "poor" $(n=20,37.7 \%)$. Overall, many studies did not sufficiently describe their methodology, which made it difficult to make determinations for items on the NHLBI tools. Items were often marked as "not specified" or "cannot be determined." A common weakness specifically for controlled intervention studies was a lack of adequate randomization. Some randomized control trials (RCTs) used a preset plan for allocating patients to intervention or control groups (i.e., even vs. odd ID numbers) instead of using computer-generated lists. Other RCTs did not provide any description for how participants were allocated. Adequate randomization is important as it provides confidence that results are attributable to the intervention rather than a difference in groups at baseline. For pre-posttests, only 3 of the 10 studies included a control group [67, 69, 70]. Without a control group for comparison, there is less confidence that an improvement between pre- and post-assessments is due to the intervention rather than mere chance. The crosssectional studies were mainly descriptive. Limited crosssectional studies used statistical analyses to determine associations between intervention and outcomes. Confounders were rarely measured and included in the analyses. Outcome measures frequently lacked validity and reliability.

\section{Discussion}

The challenges of establishing and sustaining cervical cancer prevention programs in SSA have been identified in several recent reviews [4-7]. However, the authors have found no review to date that addresses implementation strategies to overcome these identified barriers. Safe and effective prevention tools exist but are not reaching the women that need these services most. This review is an attempt to enter cervical cancer prevention into the implementation science conversation to propel the state of the science forward. Finocchario-Kessler et al. [84] conducted a systematic review of the literature between 2004 and 2014 to characterize the cervical cancer research in SSA according to four public health categories (primary prevention, secondary prevention, tertiary prevention, and quality of life). They determined that most studies focused on secondary prevention and concluded that there is a need for "implementation science research to inform feasible and sustainable strategies to maximize the number of women reached with services" [84].

Implementation science is an emerging field that aims to bridge research and practice in order to ultimately achieve desired patient and population health outcomes [85]. Historically, a significant amount of efficacy and effectiveness research conducted in controlled settings has not translated into "real-world" impact. The traditional, passive methods of dissemination (i.e., journal publishing) have not proven effective. Estimates show that it takes an average of 17 years for $14 \%$ of original research to effect practice [86]. Implementation science seeks to address this "quality chasm" by explicitly studying the processes of implementing evidence-based programs in clinical and public health settings [87]. Implementation strategies are instrumental in bridging the gap and improving the speed and rigor of research translation. The results from this review have provided insight into how study design, strategies, and outcomes have been used to study implementation of cervical cancer prevention in SSA. Since sub-Saharan Africa faces some of the highest cervical cancer rates worldwide, it is important to evaluate what has been done so far to address these challenges and contemplate how these efforts can be improved through use of implementation strategies.

\section{Study design}

While randomized control trials are the "gold standard" in efficacy and effectiveness research, these study designs are difficult to feasibly conduct in implementation research due to the use of multi-level, multi-strategy interventions [85]. It is more difficult to conduct random assignment when the level of analysis is at the organization, community, and/or country level rather than the individual level. It is also difficult to produce large enough sample sizes to create adequate statistical power. For these reasons, Brownson et al. [85] conclude in Dissemination and Implementation Research in Health, one of the seminal works to progress the field of implementation science, that quasi-experimental designs without randomization are reasonable for implementation research. However, they argue that rigorous quasiexperimental design is essential to achieving quality data that has practical use. While quasi-experimental studies may be more feasible to conduct, these designs do not produce the same level of confidence in causation as randomized control trials and make it more difficult to compare effectiveness between different studies.

In the absence of randomization, researchers can incorporate control groups, confounders, and statistical comparison of baseline group characteristics to greatly 


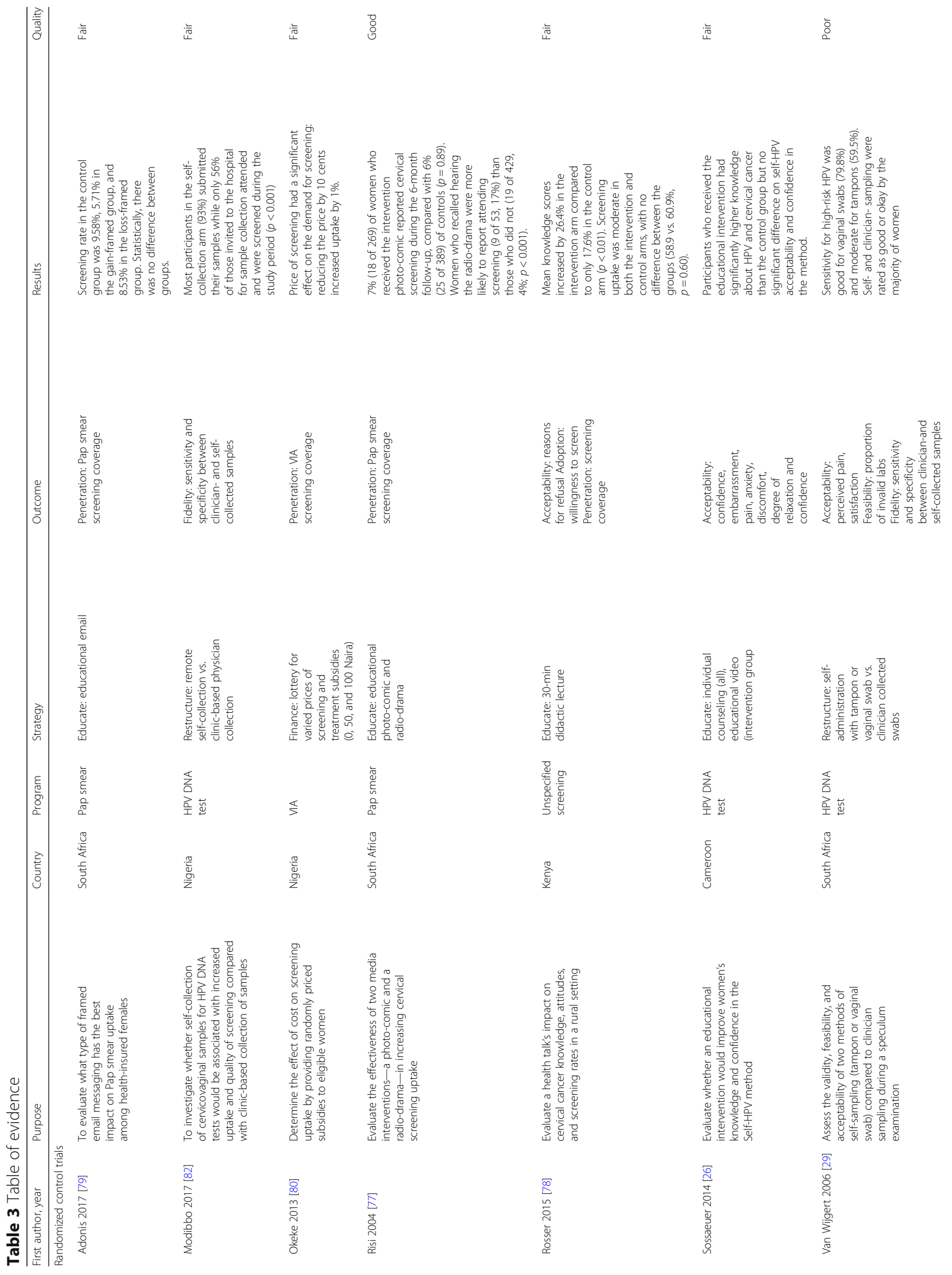


Johnson et al. Implementation Science (2018) 13:28

Page 9 of 18

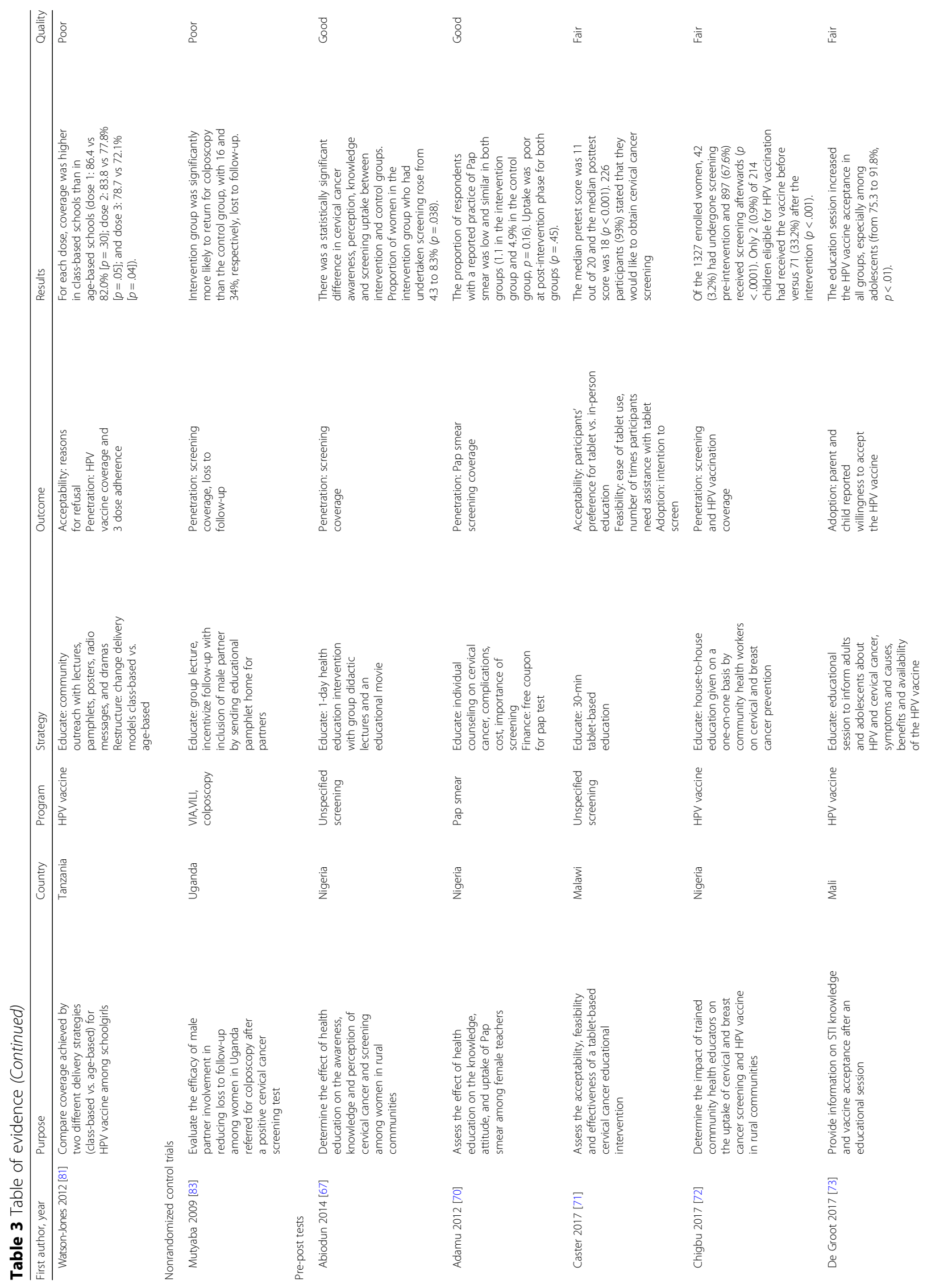




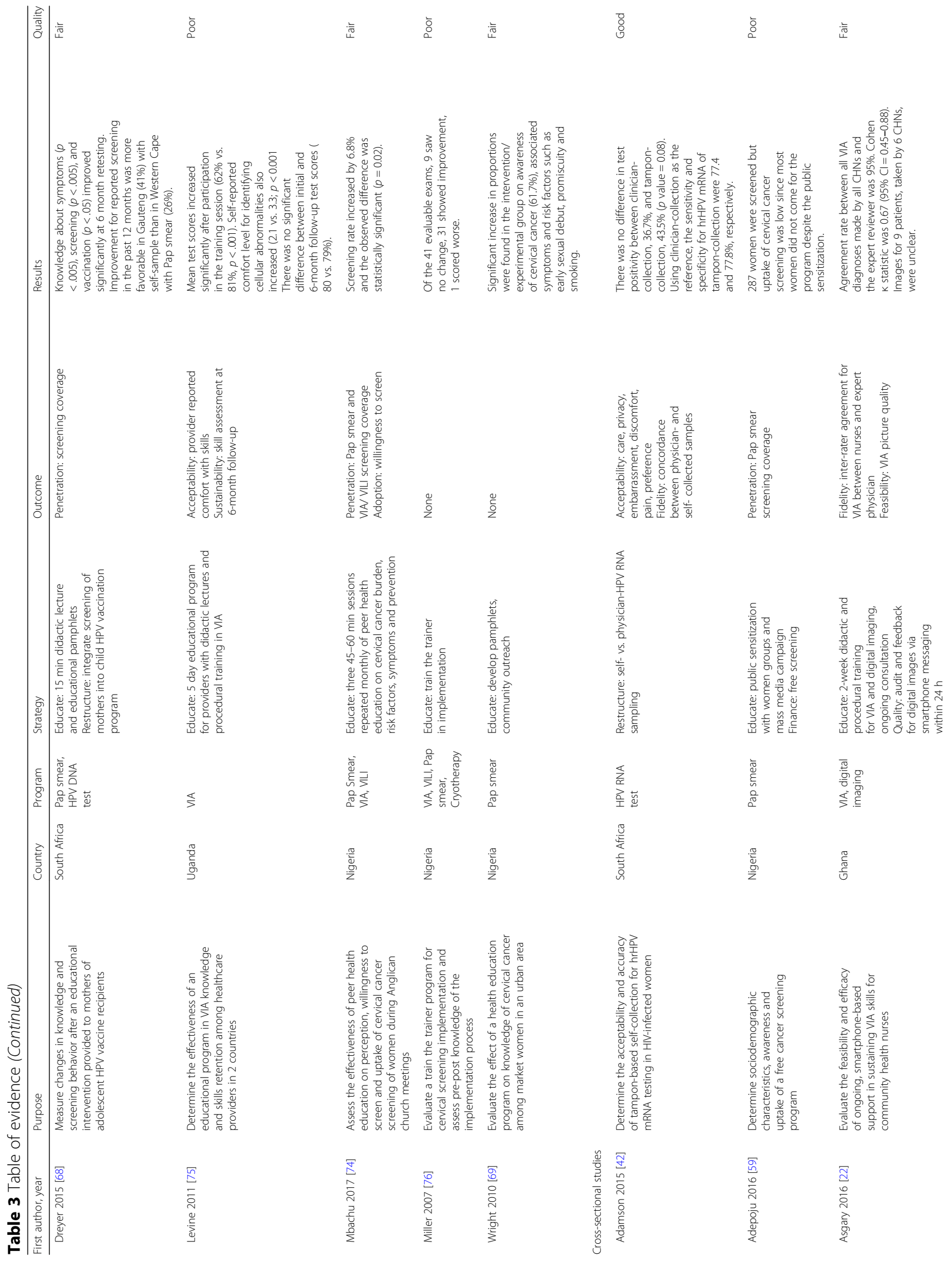




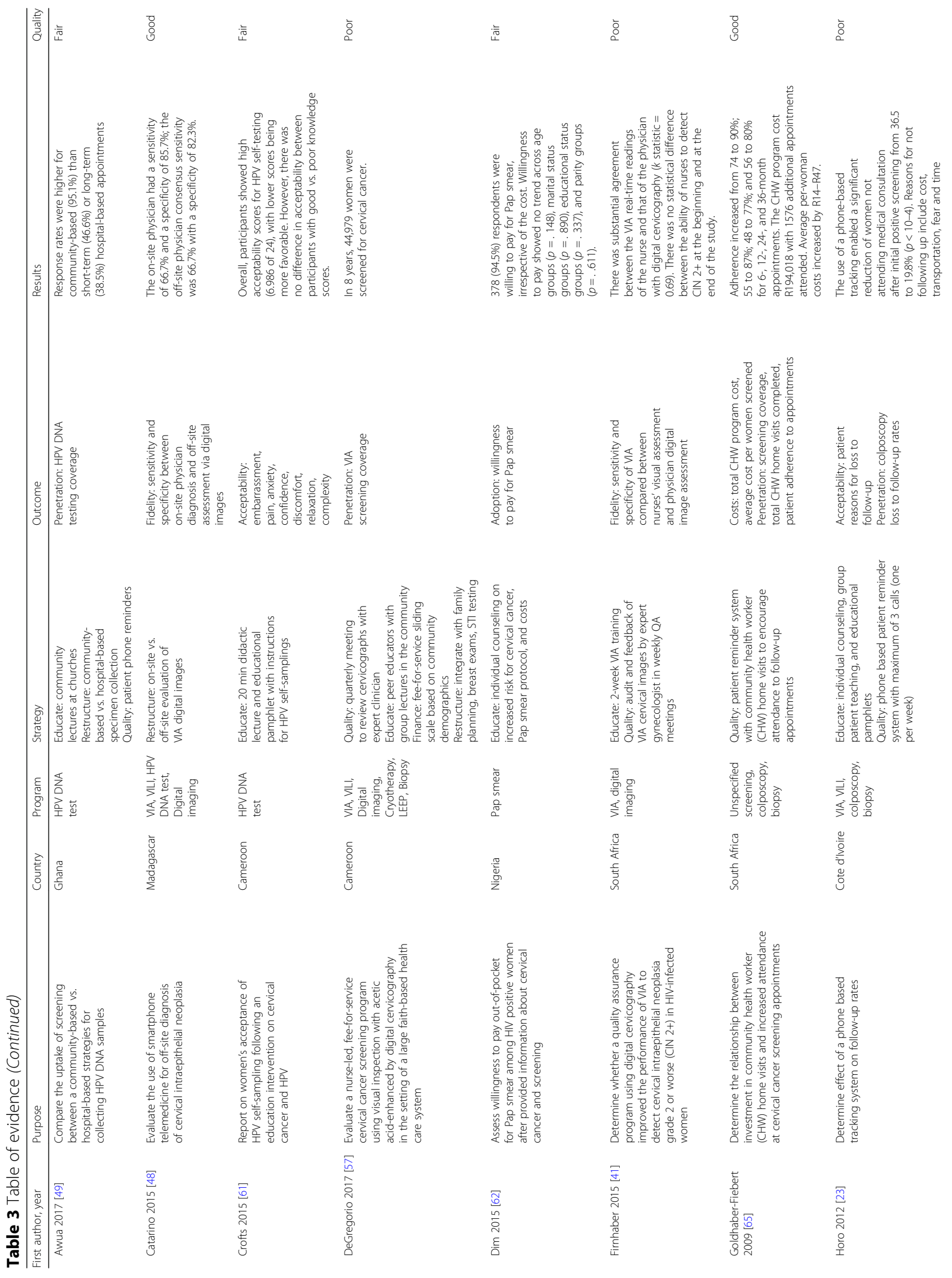




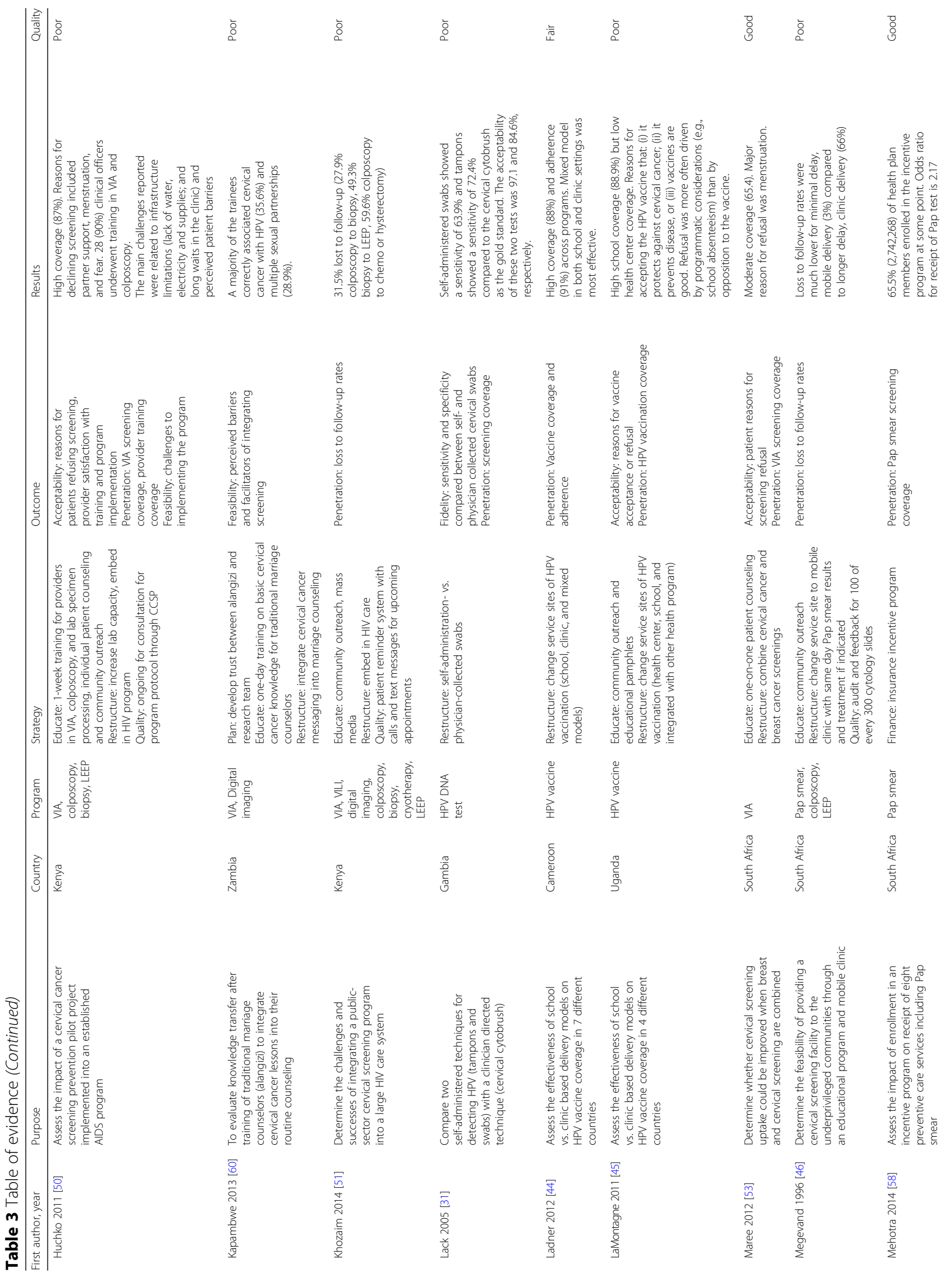




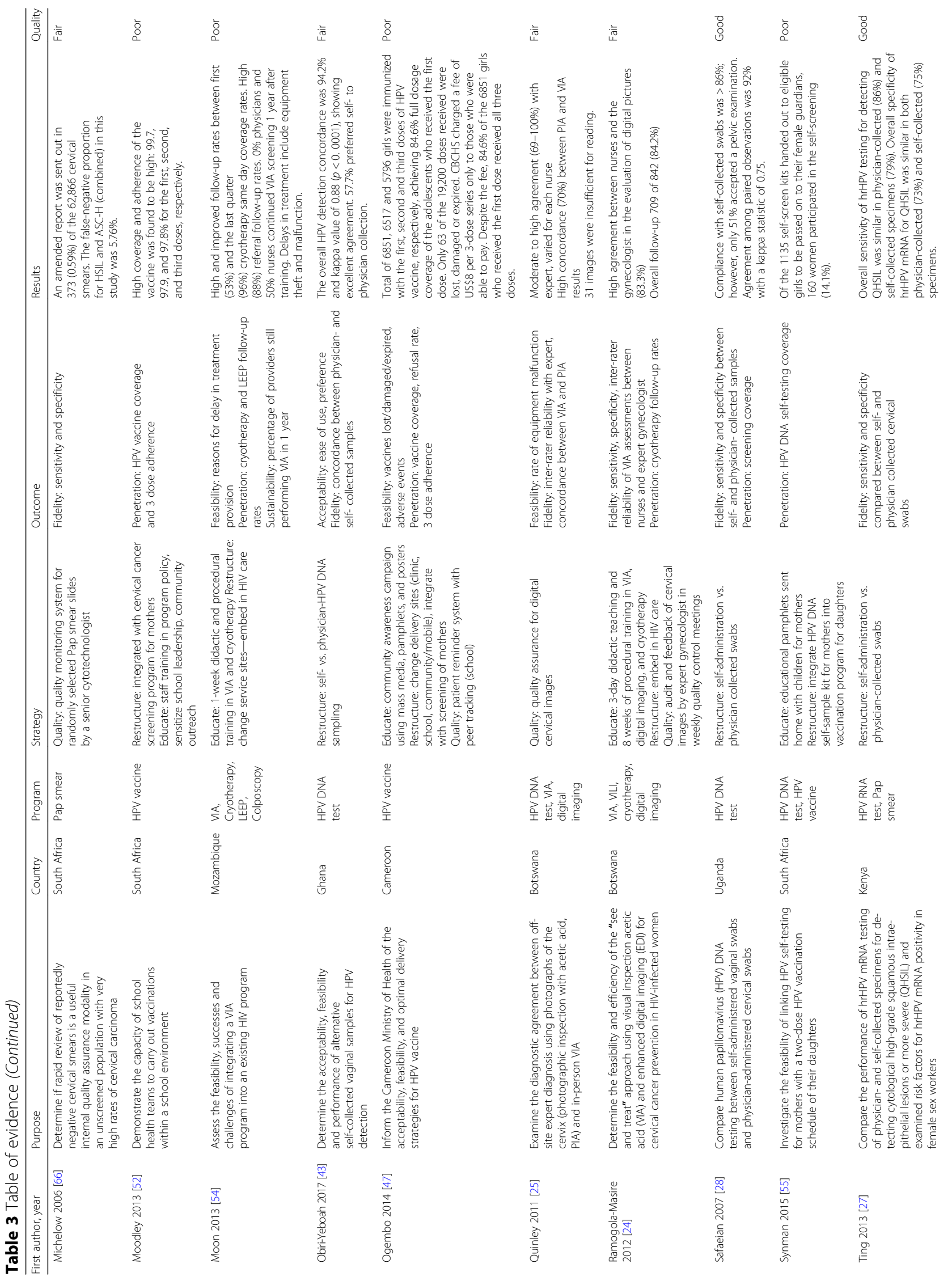




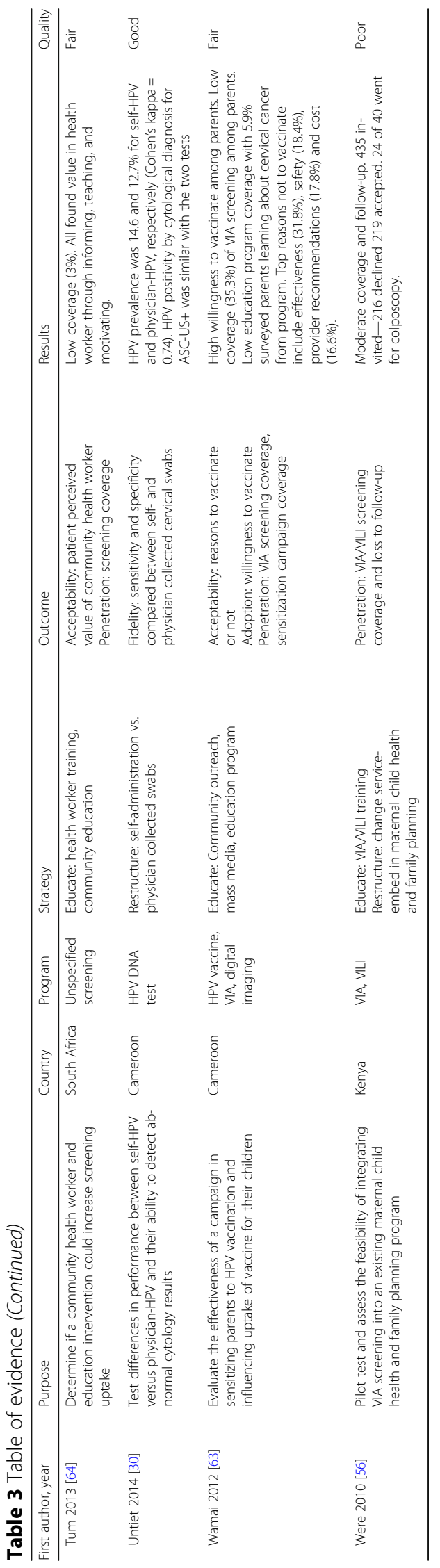


increase rigor of implementation study designs. In their assessment of 66 Cochrane reviews on implementation research, Brownson et al. [85] concluded that "many publications in the literature are still merely descriptive in nature or have weak designs without comparison or control conditions to answer critical research questions." This systematic review has produced similar results. The majority of studies are cross-sectional, descriptive studies and assessed as "poor" or "fair" quality. This review echoes the argument that there is a need for more rigorous research designs that meet the needs of implementation science questions.

\section{Implementation strategies}

Evaluating effectiveness for the various implementation strategies is difficult due to the descriptive nature of most studies, overall poor quality in study designs, and variation in outcomes measured. While educate strategies were the most popular method leveraged in attempt to improve implementation, implementation science suggests that dissemination of information is not the most effective method for creating sustainable change [88]. Within this literature review, education has also failed to produce intended outcomes. Many studies employing educate strategies have shown improvements in awareness. However, these strategies in isolation have not always catalyzed better uptake, acceptability, and/or confidence $[61,63,64,78]$. If a significant difference was observed, uptake still remained low [67, 77, 83]. These results suggest a need to diversify implementation strategies used to improve cervical cancer prevention in this context. Restructure, finance, and attend to policy context strategies can provide the organizational support required to improve implementation and overcome barriers particular to resource-limited settings.

\section{Implementation outcomes}

While there were implementation outcomes included in these studies, the overwhelming majority were patientlevel outcomes, such as symptomatology, cancer rates, cervical lesion typology, etc. For implementation studies, it is crucial to measure implementation outcomes specifically [37]. If the desired health outcomes are not achieved after an evidence-based program is implemented, the failure is typically attributed to the evidence-based program without consideration of how well the practice was or was not implemented in that particular setting $[86,88]$. If we do not measure implementation outcomes, there is no way to deduce what is ultimately influencing the patient or population health outcomes. Additionally, there is a need for continued effort in operationalizing and measuring implementation outcomes. One of the eight outcomes (appropriateness) was not measured in the review and should be considered for inclusion in future studies.

\section{Limitations}

A major limitation of this systematic review is the overall quality of evidence. "Poor" and "fair" quality ratings for the majority of studies make it difficult to make conclusions about implementation strategies and their effectiveness. Risk of bias in the study design and implementation greatly decreases confidence in the validity of results. Another limitation is that only a sample of initial articles, rather than the entire dataset, were abstracted and quality assessed by a second reviewer. However, inconsistencies were resolved through consensus before the primary reviewer proceeded with the remaining articles to ensure accuracy.

\section{Conclusions}

This systematic review elicits the need to diversify strategies that are used to improve implementation for cervical cancer prevention programs. While education is important, implementation science literature reveals that dissemination of information in isolation is not as effective in generating change [88]. There is a need for additional organizational support to further incentivize and sustain change $[85,89]$. Implementation research is difficult because interventions are multifaceted and conducted at different levels of analysis [85]. Many studies in this review included patient level outcomes but did not include implementation-specific outcomes to assess the success of implementation strategies. This review calls for an increased use of implementation science frameworks to inform the design of studies that aim to improve cervical cancer prevention in SSA. This review also calls for increased use of common terminology from implementation science for outcomes and strategies. Implementation science can help to communicate results between researchers and increase rigor of research design to better isolate impact of implementation strategies on intended outcomes.

\section{Additional file}

Additional file 1: Database-Specific Search Strategies. (DOCX 2827 kb)

\section{Abbreviations}

HPV: Human papillomavirus; LEEP: Loop electrosurgical excision procedure; NHLBI: National Heart, Lung, and Blood Institute; PRISMA: Preferred Reporting Items for Systematic Reviews and Meta-Analyses; RCT: Randomized control trial; SSA: Sub-Saharan Africa; VIA: Visual inspection with acetic acid; VILI: Visual inspection with Lugol's iodine

\section{Acknowledgements}

We would like to acknowledge Penn Libraries Open Access Publication Fund for supporting this article. 


\section{Funding}

At the time of this review, $\sqcup$ was supported with a Hillman Scholars Program in Nursing Innovation Predoctoral Fellowship, National Cancer Institute Diversity Supplement (U54CA190158_-Parent Grant), and American Cancer Society Doctoral Degree Scholarship in Cancer Nursing (DSCN-16-112-01).

\section{Availability of data and materials}

All data generated or analyzed during this study are included in this published article [and its supplementary information files].

\section{Authors' contributions}

$\sqcup, A B$, and $A T$ made substantial contributions to the conception and design of this systematic review. $\sqcup$ and CJ completed the literature search and title/ abstract review. LJ, CJ, and AA abstracted and quality assessed the included articles. All authors contributed to writing and revising the final manuscript. All authors read and approved the final manuscript.

\section{Ethics approval and consent to participate}

Not applicable

\section{Consent for publication}

Not applicable

\section{Competing interests}

The authors declare that they have no competing interests.

\section{Publisher's Note}

Springer Nature remains neutral with regard to jurisdictional claims in published maps and institutional affiliations.

\section{Received: 18 July 2017 Accepted: 29 January 2018}

Published online: 09 February 2018

\section{References}

1. GLOBOCAN 2012: Estimated cancer incidence, mortality, and prevalence worldwide in 2012. http://globocan.iarc.fr/Default.aspx (2017). Accessed 27 Apr 2017.

2. Safaeian M, Solomon D, Castle PE. Cervical cancer prevention — cervical screening: science in evolution. Obstet Gynecol Clin N Am. 2007;34(4):739-60. ix

3. Jemal A, Bray F, Forman D, O'Brien M, Ferlay J, Center M, et al. Cancer burden in Africa and opportunities for prevention. Cancer. 2012;118(18):4372-84.

4. Lim JN, Ojo AA. Barriers to utilisation of cervical cancer screening in sub Sahara Africa: a systematic review. Eur J Cancer Care (Engl). 2017;26(1) https://doi.org/10.1111/ecc.12444. Epub 2016 Feb 7

5. McFarland DM, Gueldner SM, Mogobe KD. Integrated review of barriers to cervical cancer screening in sub-Saharan Africa. J Nurs Scholarsh. 2016:48(5):490-8.

6. Randall TC, Ghebre R. Challenges in prevention and care delivery for women with cervical cancer in sub-Saharan Africa. Front Oncol. 2016:6:160

7. Chidyaonga-Maseko F, Chirwa ML, Muula AS. Underutilization of cervical cancer prevention services in low and middle income countries: a review of contributing factors. Pan Afr Med J. 2015;21:231.

8. Denny L, Quinn M, Sankaranarayanan R. Chapter 8: screening for cervical cancer in developing countries. Vaccine. 2006;24(Suppl 3):S3/71-7.

9. De Vuyst H, Alemany L, Lacey C, Chibwesha CJ, Sahasrabuddhe V, Banura C, et al. The burden of human papillomavirus infections and related diseases in sub-saharan Africa. Vaccine. 2013;31(Suppl 5):F32-46

10. Mapanga W, Elhakeem A, Feresu SA, Maseko F, Chipato T. Prevention of cervical cancer in HIV-seropositive women from developing countries: a systematic review protocol. Syst Rev. 2017:6(1):91. -017-0484-9

11. Kharsany AB, Karim QA. HIV infection and AIDS in sub-Saharan Africa: current status, challenges and opportunities. Open AIDS J. 2016:10:34-48.

12. Anorlu RI. Cervical cancer: the sub-Saharan African perspective. Reprod Health Matters. 2008;16(32):41-9.

13. Louie KS, de Sanjose S, Mayaud P. Epidemiology and prevention of human papillomavirus and cervical cancer in sub-Saharan Africa: a comprehensive review. Tropical Med Int Health. 2009:14(10):1287-302.

14. Ntekim A. Cervical cancer in sub Sahara Africa. In: Rajkumar R, editor. Topics on cervical cancer with an advocacy for prevention. Intech; 2012. p. 51. https://doi.org/10.5772/27200. ISBN:978-953-51-0183-3.

15. Denny L, Anorlu R. Cervical cancer in Africa. Cancer Epidemiol Biomark Prev. 2012;21(9):1434-8
16. Denny L, Wright T. Strategies for overcoming the barriers to cervical cancer screening in low-resource settings. Glob libr Women's Med. 2009. https:// doi.org/10.3843/GLOWM.10022.

17. Fiander AN. The prevention of cervical cancer in Africa. Womens Health (Lond). 2011;7(1):121-32

18. Cancers of the female reproductive organs. In: Stewart B, Wild C, editors World cancer report 2014 Lyon: International Agency for Research on Cancer; 2014. p. 465.

19. Mishra GA, Pimple SA, Shastri SS. An overview of prevention and early detection of cervical cancers. Indian J Med Paediatr Oncol. 2011;32(3):125-32

20. Adefuye PO, Broutet NJ, de Sanjose S, Denny LA. Trials and projects on cervical cancer and human papillomavirus prevention in sub-Saharan Africa. Vaccine. 2013:31(Suppl 5):F53-9.

21. Sankaranarayanan R, Anorlu R, Sangwa-Lugoma G, Denny LA. Infrastructure requirements for human papillomavirus vaccination and cervical cancer screening in sub-Saharan Africa. Vaccine. 2013;31(Suppl 5):F47-52.

22. Asgary R, Adongo PB, Nwameme A, Cole HVS, Maya E, Liu M, et al. mHealth to train community health nurses in visual inspection with acetic acid for cervical cancer screening in Ghana. J Low Genit Tract Dis. 2016;20(3):239-42.

23. Horo A, Jaquet A, Ekouevi DK, Toure B, Coffie PA, Effi B, et al. Cervical cance screening by visual inspection in Cote $d^{\prime}$ Ivoire, operational and clinical aspects according to HIV status. BMC Public Health. 2012;12:237.

24. Ramogola-Masire D, de Klerk R, Monare B, Ratshaa B, Friedman HM, Zetola NM. Cervical cancer prevention in HIV-infected women using the "see and treat" approach in Botswana. J Acquir Immune Defic Syndr. 2012;59(3):308-13.

25. Quinley KE, Gormley RH, Ratcliffe SJ, Shih T, Szep Z, Steiner A, et al. Use of mobile telemedicine for cervical cancer screening. J Telemed Telecare. 2011 17(4):203-9.

26. Sossauer G, Zbinden M, Tebeu PM, Fosso GK, Untiet S, Vassilakos P, et al. Impact of an educational intervention on women's knowledge and acceptability of human papillomavirus self-sampling: a randomized controlled trial in Cameroon. PLoS One. 2014:9(10):e109788.

27. Ting J, Mugo N, Kwatampora J, Hill C, Chitwa M, Patel S, et al. High-risk human papillomavirus messenger RNA testing in physician- and selfcollected specimens for cervical lesion detection in high-risk women, Kenya. Sex Transm Dis. 2013:40(7):584-9.

28. Safaeian M, Kiddugavu M, Gravitt PE, Ssekasanvu J, Murokora D, Sklar M, et al. Comparability of self-collected vaginal swabs and physician-collected cervical swabs for detection of human papillomavirus infections in Rakai, Uganda. Sex Transm Dis. 2007:34(7):429-36.

29. van de Wijgert J, Altini L, Jones $H$, de Kock A, Young T, Williamson A, et al. Two methods of self-sampling compared to clinician sampling to detect reproductive tract infections in Gugulethu, South Africa. Sex Transm Dis. 2006;33(8):516-23.

30. Untiet S, Vassilakos P, McCarey C, Tebeu P, Kengne-Fosso G, Menoud P, et al. HPV self-sampling as primary screening test in sub-Saharan Africa: implication for a triaging strategy. Int J Cancer. 2014;135(8):1911-7.

31. Lack N, West B, Jeffries D, Ekpo G, Morison L, Soutter WP, et al. Comparison of non-invasive sampling methods for detection of HPV in rural African women. Sex Transm Infect. 2005:81(3):239-41.

32. Catarino $R$, Petignat $P$, Dongui $G$, Vassilakos $P$. Cervical cancer screening in developing countries at a crossroad: emerging technologies and policy choices. World J Clin Oncol. 2015;6(6):281-90.

33. Lorincz A, Castanon A, Lim A, Sasieni P. New strategies for HPV-based cervical screening. Women's Health (Lond Engl). 2013;9(5):443-52.

34. Powell BJ, McMillen JC, Proctor EK, Carpenter CR, Griffey RT, Bunger AC, et al. A compilation of strategies for implementing clinical innovations in health and mental health. Med Care Res Rev. 2012;69(2):123-57.

35. Liberati A, Altman DG, Tetzlaff J, Mulrow C, Gotzsche PC, loannidis JP, et al. The PRISMA statement for reporting systematic reviews and meta-analyses of studies that evaluate health care interventions: explanation and elaboration. J Clin Epidemiol. 2009;62(10):e1-34.

36. Moher D, Liberati A, Tetzlaff J, Altman DG, PRISMA Group. Preferred reporting items for systematic reviews and meta-analyses: the PRISMA statement. J Clin Epidemiol 2009:62(10):1006-1012.

37. Proctor E, Silmere H, Raghavan R, Hovmand P, Aarons G, Bunger A, et al. Outcomes for implementation research: conceptual distinctions, measurement challenges, and research agenda. Admin Pol Ment Health. 2011;38(2):65-76.

38. Proctor EK, Landsverk J, Aarons G, Chambers D, Glisson C, Mittman B. Implementation research in mental health services: an emerging science with conceptual, methodological, and training challenges. Admin Pol Ment Health. 2009;36(1):24-34 
39. Damschroder LJ, Aron DC, Keith RE, Kirsh SR, Alexander JA, Lowery JC. Fostering implementation of health services research findings into practice: a consolidated framework for advancing implementation science. Implement Sci. 2009;4:50-5908-4-50.

40. National Heart, Lung, and Blood Institute: Study quality assessment tools. https://www.nhlbi.nih.gov/healthtopics/study-quality-assessment-tools. 2014. Accessed Jan 2017

41. Firnhaber C, Mao L, Levin S, Faesen M, Lewis DA, Goeieman BJ, et al. Evaluation of a cervicography-based program to ensure quality of visual inspection of the cervix in HIV-infected women in Johannesburg, South Africa. J Low Genit Tract Dis. 2015:19(1):7-11.

42. Adamson PC, Huchko MJ, Moss AM, Kinkel HF, Medina-Marino A. Acceptability and accuracy of cervical cancer screening using a selfcollected tampon for HPV messenger-RNA testing among HIV-infected women in South Africa. PLoS One. 2015:10(9):e0137299.

43. Obiri-Yeboah D, Adu-Sarkodie Y, Djigma F, Hayfron-Benjamin A, Abdul L, Simpore J, et al. Self-collected vaginal sampling for the detection of genital human papillomavirus (HPV) using careHPV among Ghanaian women. BMC Womens Health. 2017. https://doi.org/10.1186/s12905-017-0448-1.

44. Ladner J, Besson MH, Hampshire R, Tapert L, Chirenje M, Saba J. Assessment of eight HPV vaccination programs implemented in lowest income countries. BMC Public Health. 2012;12:370-2458-12-370.

45. LaMontagne DS, Barge S, Le NT, Mugisha E, Penny ME, Gandhi S, et al. Human papillomavirus vaccine delivery strategies that achieved high coverage in lowand middle-income countries. Bull World Health Organ. 2011;89(11):821-830B.

46. Megevand E, Van Wyk W, Knight B, Bloch B. Can cervical cancer be prevented by a see, screen, and treat program? A pilot study. Am J Obstet Gynecol. 1996;174(3):923-8.

47. Ogembo JG, Manga S, Nulah K, Foglabenchi LH, Perlman S, Wamai RG, et al. Achieving high uptake of human papillomavirus vaccine in Cameroon: lessons learned in overcoming challenges. Vaccine. 2014;32(35):4399-403.

48. Catarino R, Vassilakos $P$, Scaringella $S$, Undurraga-Malinverno M, MeyerHamme U, Ricard-Gauthier D, et al. Smartphone use for cervical cancer screening in low-resource countries: a pilot study conducted in Madagascar. PLoS One. 2015;10(7):e0134309.

49. Awua AK, Wiredu EK, Afari EA, Tijani AS, Djanmah G, Adanu RMK. A tailored within-community specimen collection strategy increased uptake of cervical cancer screening in a cross-sectional study in Ghana. BMC Public Health. 2017;18(1):80

50. Huchko MJ, Bukusi EA, Cohen CR. Building capacity for cervical cancer screening in outpatient HIV clinics in the Nyanza province of western Kenya. Int J Gynaecol Obstet. 2011:114(2):106-10.

51. Khozaim K, Orang'o E, Christoffersen-Deb A, Itsura P, Oguda J, Muliro H, et al. Successes and challenges of establishing a cervical cancer screening and treatment program in western Kenya. Int J Gynecol Obstet. 2014;124(1):12-8.

52. Moodley I, Tathiah N, Mubaiwa V, Denny L. High uptake of Gardasil vaccine among 9-12-year-old schoolgirls participating in an HPV vaccination demonstration project in KwaZulu-Natal, South Africa. S Afr Med J. 2013;103(5):318-21.

53. Maree JE, Lu XM, Wright SC. Combining breast and cervical screening in an attempt to increase cervical screening uptake. An intervention study in a South African context. Eur J Cancer Care (Engl). 2012;21(1):78-86.

54. Moon TD, Silva-Matos C, Cordoso A, Baptista AJ, Sidat M, Vermund SH. Implementation of cervical cancer screening using visual inspection with acetic acid in rural Mozambique: successes and challenges using HIV care and treatment programme investments in Zambézia Province. J Int AIDS Soc. 2013;15(2):17406.

55. Snyman LC, Dreyer G, Visser $\mathrm{C}$, Botha $M H$, van der Merwe FH. The Vaccine and Cervical Cancer Screen project 2 (VACCS 2): linking cervical cancer screening to a two-dose HPV vaccination schedule in the South-West District of Tshwane, Gauteng, South Africa. S Afr Med J. 2015;105(3):191-4.

56. Were E, Nyaberi Z, Buziba N. Integrating cervical cancer and genital tract infection screening into mother, child health and family planning clinics in Eldoret, Kenya. Afr Health Sci. 2010;10(1):58-65

57. Degregorio G, Manga S, Kiyang E, Manjuh F, Bradford L, Cholli P, et al. Implementing a fee-for-service cervical cancer screening and treatment program in Cameroon: challenges and opportunities. Oncologist. 2017;22(7):850-9.

58. Mehrotra A, An R, Patel DN, Sturm R. Impact of a patient incentive program on receipt of preventive care. Am J Manag Care. 2014;20(6):494-501.

59. Adepoju EG, Ilori T, Olowookere SA, Idowu A. Targeting women with free cervical cancer screening: challenges and lessons learnt from Osun state, southwest Nigeria. Pan Afr Med J. 2016;24:319.
60. Kapambwe S, Parham G, Mwanahamuntu M, Chirwa S, Mwanza J, AmuyunzuNyamongo M. Innovative approaches to promoting cervical health and raising cervical cancer awareness by use of existing cultural structures in resourcelimited countries: experiences with traditional marriage counseling in Zambia. Glob Health Promot. 2013;20(4 Suppl):57-64.

61. Crofts V, Flahault E, Tebeu P, Untiet S, Fosso GK, Boulvain M, et al. Education efforts may contribute to wider acceptance of human papillomavirus selfsampling. Int J Womens Health. 2015;7:149-54.

62. Dim CC, Onyedum CC, Dim NR, Chukwuka JC. Cervical cancer screening among HIV-positive women in Nigeria: an assessment of use and willingness to pay in the absence of donor support. J Int Assoc Provid AIDS Care. 2015;14(3):241-4.

63. Wamai RG, Ayissi CA, Oduwo GO, Perlman S, Welty E, Manga S, et al. Assessing the effectiveness of a community-based sensitization strategy in creating awareness about HPV, cervical cancer and HPV vaccine among parents in North West Cameroon. J Community Health. 2012;37(5):917-26.

64. Tum SJ, Maree JE, Clarke M. Creating awareness and facilitating cervical and breast cancer screening uptake through the use of a community health worker: a pilot intervention study. Eur J Cancer Care (Engl). 2013;22(1):107-16

65. Goldhaber-Fiebert JD, Denny LA, De Souza M, Kuhn L, Goldie SJ. Program spending to increase adherence: South African cervical cancer screening. PLoS One. 2009;4(5):e5691.

66. Michelow P, McKee G, Hlongwane F. Rapid rescreening of cervical smears as a quality control method in a high-risk population. Cytopathology. 2006 Jun;17(3):110-5.

67. Abiodun OA, Olu-Abiodun OO, Sotunsa JO, Oluwole FA. Impact of health education intervention on knowledge and perception of cervical cancer and cervical screening uptake among adult women in rural communities in Nigeria. BMC Public Health. 2014;14:814-2458-14-814.

68. Dreyer G, van der Merwe FH, Botha MH, Snyman LC, Constant D, Visser C, et al. School-based human papillomavirus vaccination: an opportunity to increase knowledge about cervical cancer and improve uptake of screening. S Afr Med J. 2015 Nov;105(11):912-6.

69. Wright KO, Kuyinu YA, Faduyile FA. Community education on cervical cancer amongst market women in an urban area of Lagos, Nigeria. Asian Pac J Cancer Prev. 2010;11(1):137-40.

70. Adamu AN, Abiola AO, Ibrahim M. The effect of health education on the knowledge, attitude, and uptake of free Pap smear among female teachers in Birnin-Kebbi, North-Western Nigeria. Niger J Clin Pract. 2012;15(3):326-32.

71. Caster MM, Norris AH, Butao C, Carr Reese P, Chemey E, Phuka J, et al. Assessing the acceptability, feasibility, and effectiveness of a tablet-based cervical cancer educational intervention. J Cancer Educ. 2017;32(1):35-42.

72. Chigbu CO, Onyebuchi AK, Onyeka TC, Odugu BU, Dim CC. The impact of community health educators on uptake of cervical and breast cancer prevention services in Nigeria. Int J Gynecol Obstet. 2017;137(3):319-24.

73. De Groot AS, Tounkara K, Rochas M, Beseme S, Yekta S, Diallo FS, et al. Knowledge, attitudes, practices and willingness to vaccinate in preparation for the introduction of HPV vaccines in Bamako, Mali. PLoS One. 2017;12(2):e0171631.

74. Mbachu C, Dim C, Ezeoke U. Effects of peer health education on perception and practice of screening for cervical cancer among urban residential women in south-east Nigeria: a before and after study. BMC Womens Health. 2017;17(1):41.

75. Levine LD, Chudnoff SG, Taylor K, Baganizi M, Banks E. A 5-day educational program for teaching cervical cancer screening using visual inspection with acetic acid in low-resource settings. Int J Gynaecol Obstet. 2011;115(2):171-4.

76. Miller D, Okolo CA, Mirabal Y, Guillaud M, Arulogun OS, Oladepo O, et al. Knowledge dissemination and evaluation in a cervical cancer screening implementation program in Nigeria. Gynecol Oncol. 2007;107(1 Suppl 1):S196-207.

77. Risi L, Bindman JP, Campbell OM, Imrie J, Everett K, Bradley J, et al. Media interventions to increase cervical screening uptake in South Africa: an evaluation study of effectiveness. Health Educ Res. 2004 Aug;19(4):457-68.

78. Rosser Jl, Njoroge B, Huchko MJ. Changing knowledge, attitudes, and behaviors regarding cervical cancer screening: the effects of an educational intervention in rural Kenya. Patient Educ Couns. 2015:98(7):884-9.

79. Adonis L, Paramanund J, Basu D, Luiz J. Framing preventive care messaging and cervical cancer screening in a health-insured population in South Africa: implications for population-based communication? J Health Psychol. 2017:22(11):1365-75.

80. Okeke EN, Adepiti CA, Ajenifuja KO. What is the price of prevention? New evidence from a field experiment. J Health Econ. 2013;32(1):207-18.

81. Watson-Jones D, Baisley K, Ponsiano R, Lemme F, Remes P, Ross D, et al. Human papillomavirus vaccination in Tanzanian schoolgirls: cluster-randomized trial comparing 2 vaccine-delivery strategies. J Infect Dis. 2012;206(5):678-86. 
82. Modibbo F, Iregbu KC, Okuma J, Leeman A, Kasius A, De Koning M, et al. Randomized trial evaluating self-sampling for HPV DNA based tests for cervical cancer screening in Nigeria. Infect Agents Cancer. 2017;12(1):1-9.

83. Mutyaba T, Mirembe F, Sandin S, Weiderpass E. Male partner involvement in reducing loss to follow-up after cervical cancer screening in Uganda. Int J Gynaecol Obstet. 2009;107(2):103-6.

84. Finocchario-Kessler S, Wexler C, Maloba M, Mabachi N, Ndikum-Moffor F, Bukusi E. Cervical cancer prevention and treatment research in Africa: a systematic review from a public health perspective. BMC Womens Health. 2016;16:29-016-0306-6.

85. Brownson R, Colditz G, Proctor E. Dissemination and implementation research in health: translating science to practice. New York: Oxford University Press, Inc.; 2012.

86. Green LW, Ottoson JM, Garcia C, Hiatt RA. Diffusion theory and knowledge dissemination, utilization, and integration in public health. Annu Rev Public Health. 2009;30:151-74.

87. Institute of Medicine (US) Committee on Quality of Health Care in America. Crossing the Quality Chasm: A New Health System for the 21st Century. Washington D.C.: National Academies Press; 2001.

88. Fixsen D, Naaom S, Blase K, Friedman R, Wallace F. Chapter 3: a conceptual view of implementation. Implementation research: a synthesis of the literature. Tampa: National Implementation Research Network, Louis de la Parte Florida Mental Health Institute; 2005. p. 11.

89. Helfrich CD, Weiner BJ, McKinney MM, Minasian L. Determinants of implementation effectiveness: adapting a framework for complex innovations. Med Care Res Rev. 2007;64(3):279-303.

\section{Submit your next manuscript to BioMed Central and we will help you at every step:}

- We accept pre-submission inquiries

- Our selector tool helps you to find the most relevant journal

- We provide round the clock customer support

- Convenient online submission

- Thorough peer review

- Inclusion in PubMed and all major indexing services

- Maximum visibility for your research

Submit your manuscript at www.biomedcentral.com/submit 